\title{
Whispering tales: using augmented reality to enhance cultural landscapes and indigenous values
}

\author{
Bruno Marques ${ }^{(D)}$, Jacqueline Mclntosh and Hannah Carson
}

\begin{abstract}
Increasingly, our built and natural environments are becoming hybrids of real and digital entities where objects, buildings and landscapes are linked online in websites, blogs and texts. In the case of Aotearoa New Zealand, modern lifestyles have put Māori indigenous oral narratives at risk of being lost in a world dominated by text and digital elements. Intangible values, transmitted orally from generation to generation, provide a sense of identity and community to Indigenous Māori as they relate and experience the land based on cultural, spiritual, emotion, physical and social values. Retaining the storytelling environment through the use of augmented reality, this article extends the biophysical attributes of landscape through embedded imagery and auditory information. By engaging with Ngāti Kahungunu ki Wairarapa, a design approach has been developed to illustrate narratives through different media, in a way that encourages a deeper and broader bicultural engagement with landscape.
\end{abstract}

\section{Keywords}

culture, narratives, indigenous knowledge, landscape architecture, augmented reality

\section{Introduction}

In Aotearoa New Zealand, where biculturalism is rooted in the national constitution and embodied in its national identity, the understanding of landscape is interpreted through two very different cultures. The indigenous Māori of New Zealand contend that their relationship with the land shapes how the cultural, spiritual, physical and social well-being of people and communities is expressed (Panelli \& Tipa, 2007). In contrast, the Western approach to landscape established by its colonisers endows "place" with contrasting notions of pragmatic utilisation and of romantic beauty (Cosgrove, 2006). Over time, the combination of this dominating European culture with the move of Māori from ancestral lands into dense urban centres has resulted in an unbalanced natural environment for both Māori and nonMāori. For Māori, the highly urbanised society has resulted in a change of natural environment, separating them from their land-based roots and culture. For nonMāori, the economic exploitation of the landscape predominantly through forestry and agriculture has contributed to global climate change and the loss of an empathetic connection with the land.

The two Aotearoa New Zealand cultures have considerable differences with respect to cultural, economic and ecological values. For Māori, human beings live in unison with nature, taking a more holistic, experiential and belief-based approach which emphasises the unique as well as the transcendental. The concept of nature, or landscape, is developed through social interactions and is about the perceptions that people have of a certain place, the unique rather than the transcendental. The landscape is a part of a circle of life, establishing a holistic perspective that is passed on through oral traditions, narratives and storytelling to future generations, celebrating the spiritual and natural history gained over centuries (Menzies, Renata, \& Whaanga-Schollum, 2016; McKenzie, 1985). As a result, Māori have a deeply connected identity with specific landscapes, and their cultural and ancestral history is shared through the biophysical components of landscape (whenua), which allow a person to determine their place in the world (Murton, 2012). Traditional Māori tikanga (customs and traditions) provide the connectedness to landscape, where self is literally a part of landscape. This connection extends not only the physical realm but also social, ancestral and spiritual realms (Mark \& Lyons, 2010). In contrast, the Western understanding of land and landscapes is strongly influenced by a positivistic, scientific and utilitarian relationship between people and land (Peet \& Watts, 2004). Thereby, knowledge is seen as rational and goal-oriented, and the world is understood as a singlelayered construct of universal principles, where humans are superior to any sort of living creatures, pursuing

School of Architecture, Victoria University of Wellington, New Zealand

\section{Corresponding author:}

Bruno Marques, School of Architecture, Victoria University of

Wellington, PO Box 600, Wellington 6140, New Zealand.

Email: bruno.marques@vuw.ac.nz 
material assets. There is also a strongly cultural need to control and utilise the land as it is also understood as a source of food, minerals and natural resources that can be extracted for human gain. The nature-culture-dualism is conducive to the exploitation of nature, the development of ethnocentrism and the dominance of production as the preeminent form of relation to the world (Phillips, 2007). It is also conducive to an understanding that landscape is related directly with the aesthetical beauty of gardens and the natural beauty of the countryside (Kemal, 1999).

The difference between cultures can be explored through patterns of settlement and advances of technology. Traditionally, Māori lived within the landscape, relying on the surrounding environment for sustenance (Yates, 2006), living in small hapu (familial groups) near water bodies which provided water and food. Buildings were constructed from locally sourced materials such as timber and raupō (bulrush), a wetland plant that grows on the edges of ponds, lakes and slow flowing rivers and streams. Settlements were spatially distributed along freshwater tributaries as opposed to parallel to the seashore. With the arrival of European settlers, a new model of settlement was introduced. Infrastructure such as roadways and services was introduced; the size of settlements were greatly increased; the orientation of the settlement was towards the sea; and the buildings were constructed from imported materials as well as locally sourced materials that were processed using imported machinery and finished with imported technology, such as paint. The development of this environment occurred quickly and ubiquitously, lacking connection to the immediate landscape (Mennella, 1997). With development and urbanisation as well as the relocation of Māori from rural to urban areas, the reliance on the specific fauna of the local environment became less necessary and altered Māori perspectives, separating biophysical functions from the built environment.

The belief that the urban environment is an entity apart from nature has dominated Western thinking through history, aggravating and arguably creating environmental problems such as polluted air and water, increased energy demands, flooding, drought, among others (Dakin, 2003; King, Smith, \& Gracey, 2009; Vining, Merrick, \& Price, 2008). As cities increase in size, the issues become more pressing and the establishment of surrounding rural environment becomes more important. Lower population densities in these environments provide more opportunities to reconnect with nature. However, for many, both Māori and non-Māori, the connection to landscape as an everyday experience has been lost and the knowledge that accompanied it also is forgotten. For Māori in particular, the combination of loss of land and migration from ancestral lands to urban areas has contributed to a widespread disengagement from their turangawaewae (domicile where one has the right to "stand") or whanau (family) (Borell, 2005; Williams, 2003). The broken link to the landscape also severs connection with history, knowledge and stories that were transmitted orally from generation to generation, endangering their sense of identity and community (Chris, 2000; Gentz \& Kramer, 2006; Lieberman, 2009).
The standard Western practice of providing landscape information through the use of interpretative boards and visitor centre posts no longer effectively engages people with the stories of the land. Contemporary visitors demand sophisticated interpretation and increasingly, our built and natural environments are becoming a hybrid of real and digital entities where objects, buildings and landscapes are linked online through websites, blogs and instant messaging (de Souza e Silva, 2006). Younger generations in particular have a strong relationship and engagement with digital devices, relying increasingly on these and other advanced technologies (Murthy, 2008), creating challenges and benefits. While the rise in technology use means access to information can increase and can open the door to new systems that draw people together (Kalay, 2007), the disconnection from a more social face-to-face interaction can be a crucial loss for some cultures (Burgess, 2006).

This article explores opportunities for re-establishing a relationship between land and people through the reconnection of the biophysical attributes of the landscape with storytelling and oral narratives, using meaningful virtual objects with information in a mobile setting. Employing augmented reality (AR), a new relationship can be created through the re-introduction of narratives using visual and aural elements that simulate people's imagination of a hidden past. Leveraging from the reliance on mobile technologies through augmentation, hybrid and designed spaces can overlay the physical attributes of an existing environment using media to articulate site-specific stories. This research contributes to the examination of new and emerging mobile environments and the use of digital technologies by proposing a refined methodology for cultural sustainability in the landscape.

\section{Methodology}

This research project uses location-based AR to overlay meaningful Māori sites with imagery, video and/or audio of narratives that users can access through their mobile devices. To accommodate the complexity of the experiment by acknowledging individual interpretation of values and experiences, an interpretative paradigm with an ontological belief was followed as a way to address the multitude of realities. Simultaneously, this allows for those realities to be constructed by the individual within their own personal frames and contexts (Crotty, 1998).

First, oral narratives were identified and connected to their landform, then combined in an added layer of technology, which in this case was AR. Similar approaches have been used before to explore historical or cultural heritage contexts (Damala, Cubaud, Bationo, Houlier, \& Marchal, 2008; Irving \& Hoffman, 2014; Mohammed-Amin, 2010; Vlahakis et al., 2001) focusing on artefact or place; however, little has been undertaken in the landscape context. In this study, the Māori cultural narratives and connections to the landscape were explored through the use of the software application, HP Reveal, which can overlay data or information such as text, images and multimedia threedimensional (3D) models, by aligning the device with 


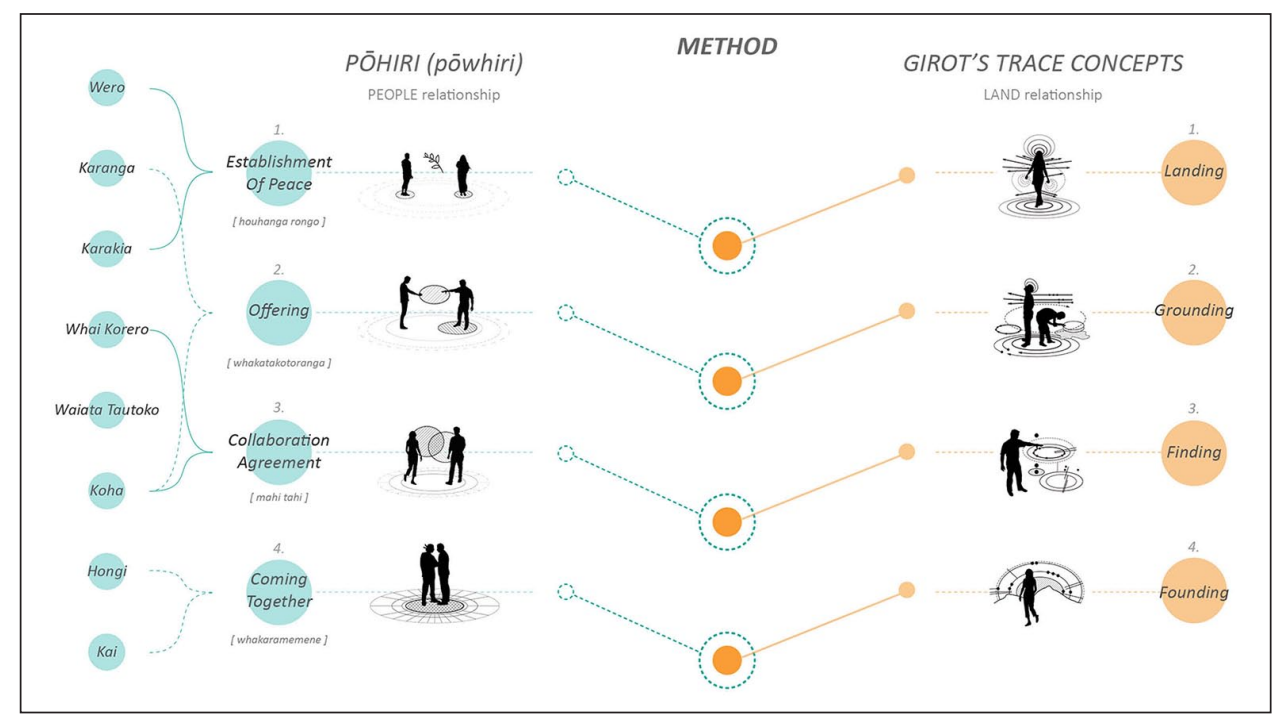

Figure I. Illustration of the two processes based on Girot's four traces and the Māori process of pāhiri. Source: Authors' own.

trigger objects. The trigger objects were vertical elements such as posts or tree bark patterns, which activated the AR element. The trigger is identified through the camera of the smart phone device, and the digital information is locked onto that image. Through the trigger image, a visual composition is added containing the information overlaid. This may include photography, illustrations, animations and voice recording. In this case, the digital element was a hand sketch highlighting key features and drawing out essential elements of the relevant story or ideas from the narrative, creating a visual representation overlaid on the existing environment.

To address the wider research question guiding the study, "Can the oral narratives of Aotearoa New Zealand's landscape be reimagined and represented through the merging of existing landform and augmented reality?" Girot's (1999) four-trace process was applied in conjunction with the Māori process of pōhiri (or pōwhiri). Christophe Girot's framework is one of the few landscape theories that engage with the exploration of a culture not one's own. Using a cumulative process of interpreting and reconstructing sites, Girot emphasises the need for direct engagement with sites, experiencing places intuitively and privileging phenomena that are unique to that place. The Māori process of pōhiri (or pōwhiri) situates the case study within Aotearoa New Zealand and establishes culturally appropriate rituals of encounter. These two methods of enquiry both adopt a phenomenological approach, which allows for both a deeper understanding of the site and its relevant processes in the wider environment and the interactions with people and the landscape.

Girot (1999) uses the term "paysage" to refer to both the visible and invisible aspects of landscape in relation to people and the environment. This acknowledges the importance of an individual's experience and the reactions and perceptions towards that environment. The four-trace concepts include landing, grounding, finding and founding. Each step in the process indicates a stage of experience as an individual gains a sense of a place, of the known and the unknown. The process also allows for distinctive perspectives when viewing a site by accessing different "lenses" to draw from our past experiences, which directly aligns with the indigenous perspective of pōhiri.

The process of pōhiri is widely known as a welcoming ceremony. It draws on the spiritual connections between different groups when coming together, where the hosts (tangata whenua) welcome the visitors (manuhiri). There are several outlined stages that vary only slightly between tribes. For the representative of Ngâti Kahungunu ki Wairarapa, the following stages were identified: wero (challenge), karanga (the call), karakia (prayer), whai korero (spoken search), waiata tautoko (support song), koha (gift), hongi (greeting) and kai (food). The different stages indicate the progression from the initial challenge and meeting to the removal of the tapu (sacredness) of the situation and closing of the process.

\section{Creating a bicultural framework}

To develop an appropriate framework which acknowledges both indigenous and non-indigenous constructs, the two models were grouped into four categories. Girot's trace concepts provide a framework for a non-indigenous encounter with the land and commence with the initial "landing" of the individual in a foreign place. This is followed by the "grounding" of that individual through close observation, the "finding" of meaning in the landscape and finally the "founding" of a meaningful design. In contrast, the pōhiri provides a framework for personal encounter by an indigenous person with "another" in the context of a familiar landscape, that of the marae (meeting house). The pōhiri is a structured process which establishes a peaceful union (houhanga rongo), an offering which acknowledges an equal exchange (tuku) and a collaborative agreement (mahi tahi), and is finalised by a coming together (whakaramemene) (Figure 1). The merging of these two processes 


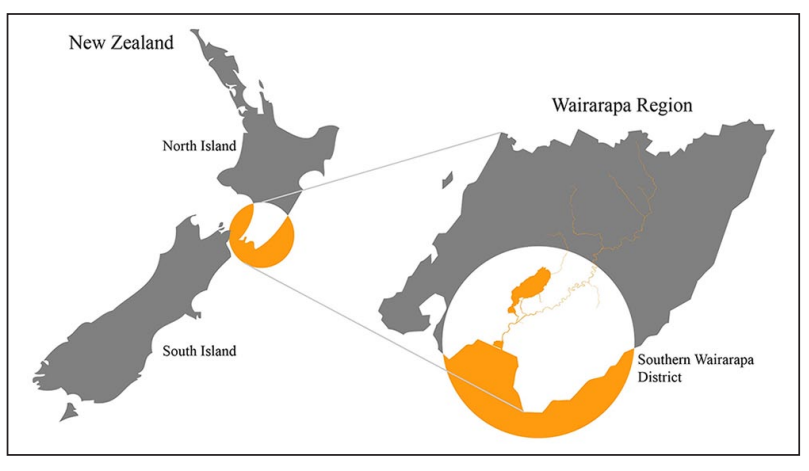

Figure 2. Location map of South Wairarapa District. Source: Authors' own.

grounded the research within the realm of bicultural landscape architecture by acknowledging the human aspect of landscape through the adoption of Māori traditional practices and perspectives. Through the merger of these two processes, design testing and decisions were made for different sites along the shore of Wairarapa Moana (Lake Wairarapa). Augmented reality was then paired with the designs as a way to allow an engagement with a different perspective of the local oral narratives of the landscape. Stories and information were sourced through the engagement with the local Māori tribe and a senior Māori representative from Ngāti Kahungunu ki Wairarapa verified the final product as part of safeguarding their taonga (treasures) and whakapapa (lineage) or meaning. For Ngāti Kahungunu ki Wairarapa, the taonga-ness of an object, digital or not, is primarily determined by the quality of the relationships that a specific object has to someone. Those relationships are part of the tribe's collective history and kinship networks (Ngata, Ngata-Gibson, \& Salmond, 2012).

The potential advantages of this process are significant. The framework addresses both indigenous values and Western values, incorporating both people and land relationships. Here, biculturalism can be defined as an equal partnership between two groups which in turn supports cultural diversity, acknowledging at the same time that Māori are the tangata whenua, or the original inhabitants of Aotearoa/New Zealand. The technology permits the user to remain grounded in the context of a specific site, while engaging in a direct relationship with cultural values of that landscape. Other layers of that place, such as music or voice recordings as well as haptic experiences through vibration, can also be introduced without altering the existing environment.

\section{The case study}

The Wairarapa region was selected as the site for this project due to the rich history and the many oral narratives that are a part of the landscape (Figure 2). The region, known for its abundance of land, water and soil fertility as well as long occupation by Māori tribes such as Ngāti Kahungunu ki Wairarapa, proved a useful testing ground for the development of this research. The Wairarapa was selected for its proximity to Wellington, the capital city of Aotearoa New Zealand. Recent infrastructure developments, such as motorways and railways, as well as the land use changes to accommodate a monoculture agriculture and extensive beef and sheep grazing, served to degrade the natural resources and increase flooding events. This radically modified the physical environment, including changing; lake boundaries and water levels, land uses and native vegetation; all of which have impacted the oral narratives.

Specific sites in and around the region were selected in consultation with a senior representative from Ngāti Kahungunu ki Wairarapa iwi (tribe), who also provided many stories both general and specific to their tribe about this region. Other Māori iwi representatives were closely involved with the biophysical augmentation and illustration of narratives in order that any images requiring resolution could be addressed and any issues resolved. The project adhered to appropriate ethical guidelines and cultural protocols for working with Māori iwi (tribes). All narratives provided remain the propriety of the iwi; however, the illustrations form an important part of the narrative and Māori consent was obtained for the use of these illustrations in academic publications and conference presentationshuman ethics application number 0000026003.

Central to the Wairarapa region is a large lake, Wairarapa Moana (Lake Wairarapa), which served as the focal area. Many stories were related to or around this water body. A route was proposed from the top of the lake down to its southern base. A cycle or driven route was proposed with multiple stop-points along the edge of the lake where particular stories or narratives were portrayed. This meant that certain narratives were physically visible in the landform and others had specific historic or cultural significance. In sum, nine sites were selected where the unifying criteria for the sites were the interconnectedness of narratives and their association with the place. Eight different stories were explored, mainly one per site with the exception of the first and last sites, which shared the same narrative (Table 1). Landscape architecture design interventions for each of these sites were iterated taking into consideration both the physical attributes of the site and the technology-related interactions.

\section{Results}

Girot's trace concepts fit well with Māori pōhiri protocols as it brings to the forefront the concept of biculturalism as an equal partnership between two groups that values and supports cultural diversity. Mutual respect and communication, including each other's vision, focusing on solutions and understanding the land together, all enable collaboration and innovative outcomes to bring the community together. In meetings, Māori participants frequently refer to the physical attributes of the landscape, which included mountains, hills, cliffs, gullies, rivers and lakes. Wāhi tapu, understood as sacred places, were identified by the iwi/ tribe as either a general location or a specific site which had traditional, spiritual, religious, ritual or mythological values. Places may be urupā-related to birth or death; sites 
Table I. Selection of site through the relationship between oral narrative and the physical attributes of the landform.

\begin{tabular}{llll}
\hline Site & Narrative & Site typology & Physical attributes \\
\hline I & Ranginui and Papatūānuku & Reserve & Expansive, access to lake \\
2 & Ruaumoko & Roadside & Flat, no vegetation \\
3 & Rakai Uru & Reserve & Secluded, dense vegetation \\
4 & Maui's Fish & Reserve & Open public area, lake access \\
5 & Naming of Remutakas & Roadside & Dramatic shift in topography, views \\
6 & Rongomai Whakatika & Roadside/bridge & River edge condition \\
7 & Tane & Roadside & Enclosed vegetation, forest \\
8 & Rakai Uru-eels & Roadside lookout & Expansive, semi-coastal \\
9 & Ranginui and Papatūānuku & Reserve/path & Rough exposed conditions, expansive \\
\hline
\end{tabular}

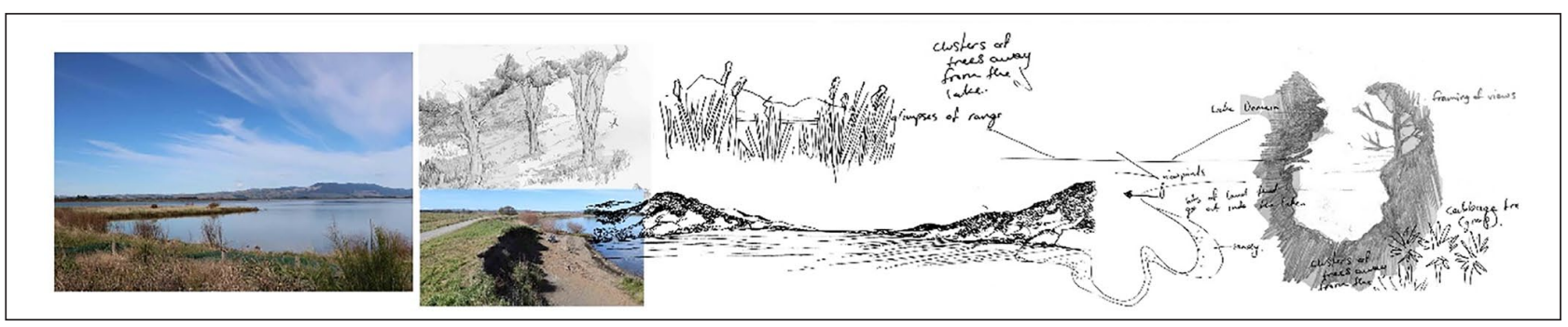

Figure 3. Landing collage, site sketches and photos exploring the relationship between the oral narrative and the physical attributes of the landscape.

Source: Authors' own.

related to ritual, ceremonial worship or healing practices; places imbued with mana (spiritual power) of chiefs or tūpuna (ancestors); battle sites or other places where blood has been spilled; or landforms like mountains and rivers having traditional or spiritual associations. Combining Girot's land-based approach with the Māori people-based approach allowed a complexity and richness of landscape interpretation, otherwise unattainable.

\section{Houhanga rongo + landing}

For Māori, there is a transparent relationship between the natural environment and the spiritual world which assisted this research in crafting design scenarios for the different sites as well as testing the AR simulation. The initial stage of houhanga rongo and "landing" was deemed the most important as the user gains their first impressions of the site and establishes a "hunch" for the site, generally proving to be a close and personal encounter for the designer. To identify the sense of place, the researcher visited the site both individually and with local tribe members to grasp the nature or mauri (spirit) of the site. Hand drawings and sketches (Figure 3) were used by the researcher to understand and develop the narratives at play.

\section{Tuku + grounding}

The second stage follows the initial discoveries of houhanga rongo and "landing", unveiling the visible and invisible layers of the site. Tuku takes on the meaning in this context as the presentation of something, in particular the presentation of information. This implies that the land is presenting the information and the researcher is taking part in this discovery through investigation. Accordingly, a deeper understanding of the biophysical template was developed through the examination of the specifics of soil, climate, water, ecology and history. The layering of this information allowed the uniqueness of the site to be recognised (Figure 4).

In contrast to houhanga rongo and "landing", tuku and "grounding" are constant and continually discoverable. The "grounding" stage included several visits to site, each time documenting new findings which were layered upon the existing information found in the landing stage. Further mapping of the stories that were related to the specific parts of the landscape allowed for the identification of key areas. The nine sites selected through this process are shown in Figure 5.

\section{Mahi tahi + finding}

The mahi tahi and "finding" stage involved a searching and an outcome. The outcome was formed from the evolving understanding of the identity of the site and was varied as different activities yielded different site-specific discoveries that were at times tangible and at other times intangible. For example, a location along the Lake Wairarapa provided a viewpoint to the vastness of the lake as well as to the surrounding hills. This specific site has a strong connotation to a narrative where in Māori mythology, the cultural hero Māui fished up the North Island (Te Ika-a-Māui or the fish of Māui). One of the eyes of the fish is Lake Wairarapa. This site, which was once a lush wetland ecosystem, is now largely used as a thoroughfare and is 


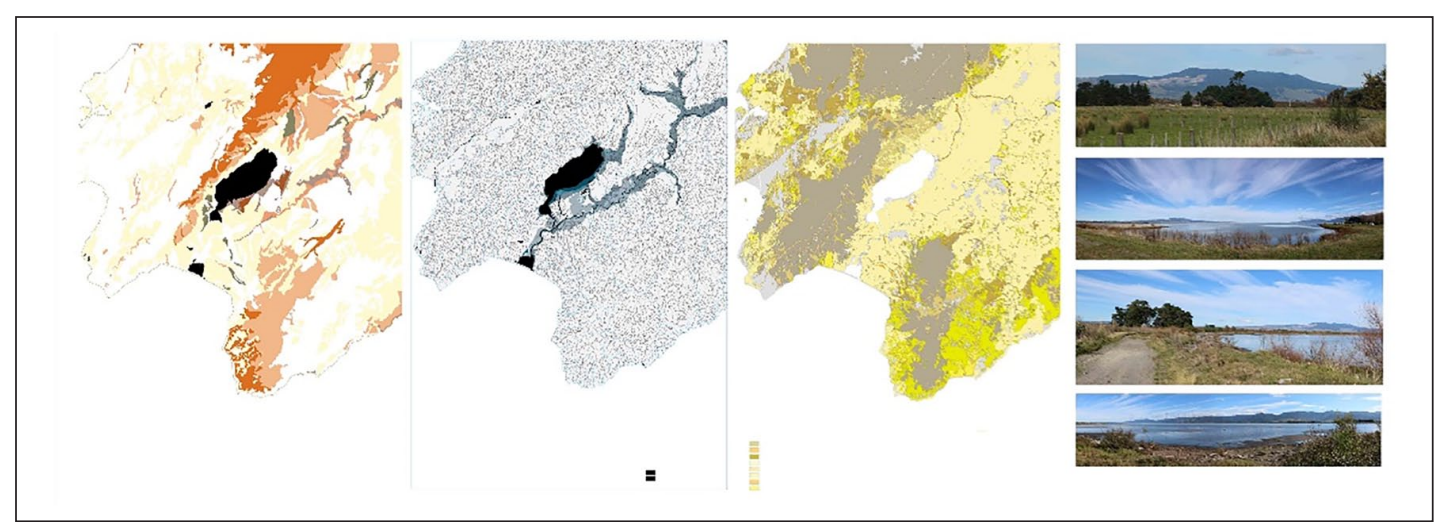

Figure 4. Site mapping and photos exploring the biophysical context of the sites. Source: Authors' own.

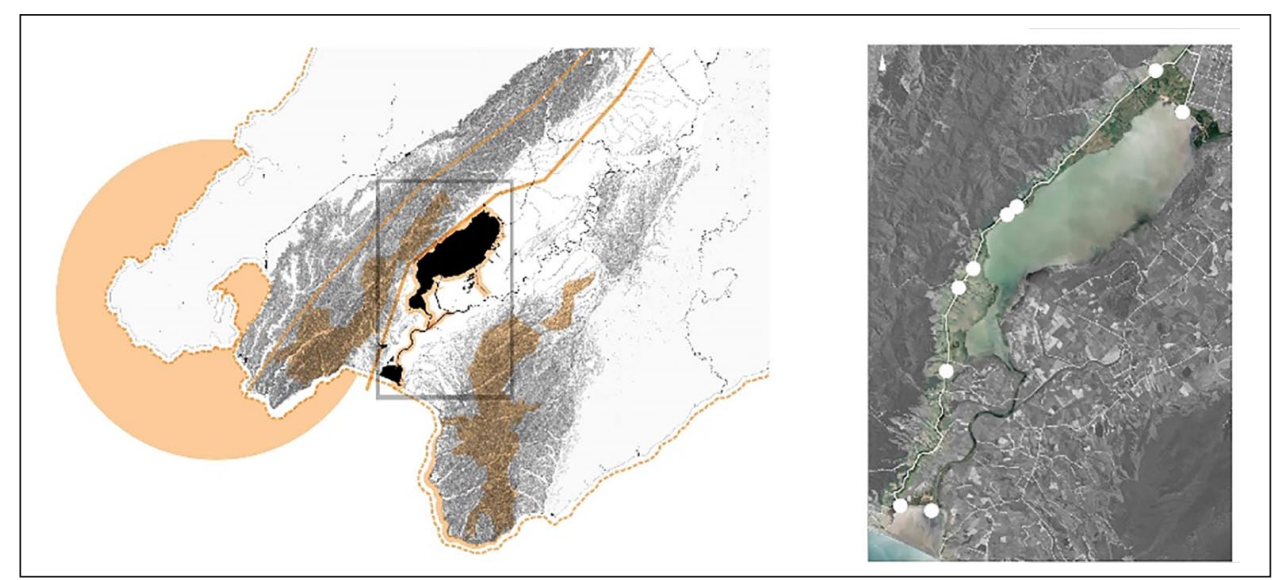

Figure 5. Map showing the location of narratives across the South Wairarapa region (left) and the selected nine sites along the Wairarapa Moana (right).

Source: Authors' own.

susceptible to flood and erosion damage. The process of "finding" involved bringing together tangible experiential physical qualities with intangible elements expressed in the narratives of the site.

Four types of design analysis (ground plane, structure, vegetation experience and platform) were then used for each of the nine sites to establish the existing conditions and findings and to start to explore potential alterations and modifications (Figure 6).

\section{Whakaramemene + founding}

The final stage involved a synthesis of the previous three steps, bringing together the different stages of houhanga rongo and "landing", tuku and "grounding", and mahi tahi and "finding", as a reaction to existing conditions. The meaning of whakaramemene, a coming together, required that all elements discovered were combined to influence final design decisions. Through this process, new elements appeared, ranging from the conservative to the innovative and varied in time and in impact (Figure 7). Girot (1999) describes this "founding" stage as the extension of the legacy of a place. For Māori, the defined pōhiri stage of whakaramemene reflects the intimacy with the act of hongi (sharing of breath). In relation to the landscape, this encourages a close perspective thinking about the entirety of the details while taking into account the landscape as a whole from the information discovered.

The introduction of AR allows for a synthesis of the layered elements providing a narrative which can overlay the existing landscape. This application of technology with Girot's strategy of narration, and the inclusion of indigenous knowledge (Mātauranga Māori) through the pōhiri process, encourages a strong relationship with the existing environment and allows the introduction and influence of outside elements into the overall mauri (spirit) of the place. Augmented reality is an element that is not a part of the existing environment, yet it allows a greater engagement with the history of that landscape-in this case, the intangible values that come with the oral narratives of a place.

\section{Discussion}

The chief aim of this research project was to explore how landscape architecture and technology can work together to encourage engagement with the oral narratives of landscape. When considering the full complexity of a cultural 


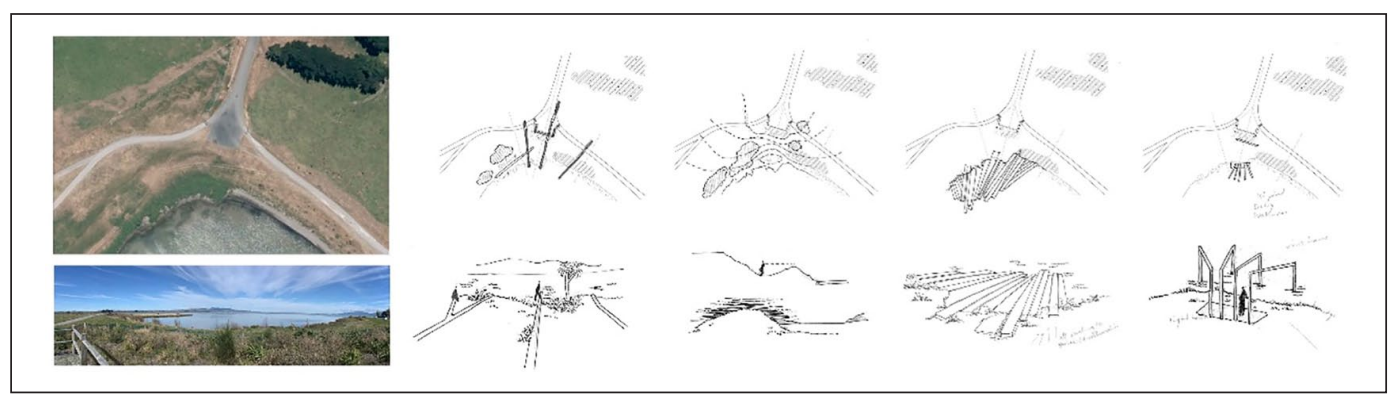

Figure 6. Design testing in plan and perspective of site 0I, which explores the narrative of Ranginui and Papatūānuku. Source: Authors' own.

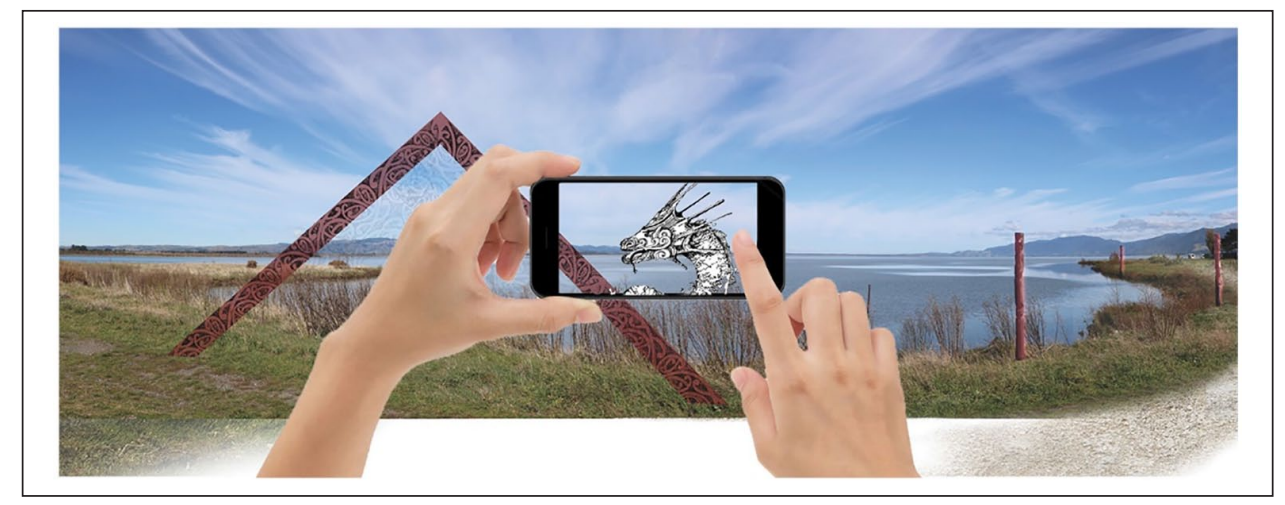

Figure 7. Exploration of AR elements on site. Source: Authors' own.

landscape and its bicultural audience, a new approach is required. Disciplinary theories and tools can be used to bridge the gap to reality and philosophical theories and can assist with addressing the complexity of combining culture, history narrative and technology (Eve, 2012). The discourse surrounding cultural landscapes and narrative can be advanced through an exploration of the relationship between landscape and technology.

\section{Culture and landscape}

Using these two media can contribute to a deeper understanding of Māori and the narratives that create a bicultural landscape. The methodology employed was appropriate for this research as it allowed a subjective interpretation of cultural values, which enabled site discovery and development through a more appropriate non-text strategy. However, the concept of cultural landscapes was found to vary across disciplines. In 1994, Birnbaum defined cultural landscape as a geographical area that included resources of both the cultural and the natural, with organisms or wildlife that resided within and which can be associated with historic events, activities or a person, or exhibiting other cultural or aesthetic values. This refers to a richness of complexity that landscape retains with many associative layers of meaning and history. Robertson and Richards (2003) suggest that landscape is the product of human values, meanings and symbols, arguing that culture is the most important factor in terms of deriving meaning in landscape. Culture therein implies a shared set of characteristics, histories or traditions
(Merriam Webster, 2018). Human interaction with the land gives a richness to the history of the landscape and represents the "process out of which they have emerged" (Robertson \& Richards, 2003, p. 2). This highlights the importance of human interaction and relationship with the landscape through a deeper understanding of how the land and its processes have occurred over time.

For the discipline of landscape architecture, the cultural landscape is broadly a series of human interactions and perceptions within place. In the context of Aotearoa New Zealand, land is particularly significant to Māori and is based on a historic reliance on the landscape for resource, sustenance, transport, prestige and hospitality (Marques, Grabasch, \& McIntosh, 2018). As such, there is arguably a deeper relationship with respect to what can be taken from the land and the importance of giving back to the land through the sense of kaitiakitanga (guardianship). Unlike Western culture where most stories are captured in books, paintings, displays or artefacts, for Māori the cultural stories which make sense of the landscape are passed on orally, and as such are inaccessible to anyone other than the immediate whanau (family) and those specific others with whom they elect to share. As suggested by Menzies et al. (2016), for Māori, landscape is more than the aesthetics and beauty of a vista and is directly related to specific people and their perceptions and connections. The Māori word whenua highlights this construct through its definition as both "land" and "placenta". This relates to the Māori tradition where the placenta of a newborn child is buried in the ground, symbolising the direct relationship that that child 
has with the land of their birth. The responsibility and relationship with the land are thereby established from the very beginning of life, reinforcing the strength of the humanland connection.

Richness and depth of meaning are what connect Māori with landscape and therefore contribute towards establishing identity. Murton (2012) discusses the importance of identity and the role of body, self and place where landscape is key. The Māori term whakapapa has a direct meaning as "to place layer upon layer" where identity is created by many layers or elements of self in the world. Māori identity is in the landscape where their whanau (family) live and in the interactions of the world, be they physical, spiritual or emotional. "To know a rock is to know its respective genealogy" (Murton, 2012, p. 92). The many layers of the interpreted landscape illustrate the connection of Māori to the land as they host stories of knowledge, learning, tradition and family (ancestors) aligning with their values, meanings and symbols. To know the landscape is to know its cultural value and history (Royal, 2007). Similarly to what Muru-Lanning (2012) argues, in this project Māori representatives were given the liberty to include cultural signifiers in discussions as a way to recognise their important role in mediating the relationship between Māori communities and their resources. Through these constructs, a definition of cultural landscape can be articulated as the interrelationship between human society and the natural environment, recognising the intangible values that indigenous people place on landscape (Marques et al., 2018; McIntosh, Marques, \& Hatton, 2018).

\section{Narratives and landscape}

Narratives bring to life the essence of an experience that is associated with a specific place. As Māori culture has a strong relationship to land and, rooted in that, a strong notion of identity and spirituality, experiences of place can contain tangible and intangible values. The process of the telling of these stories traditionally involved a long manystranded chain of both speakers and receivers operating in a time and space (Metge, 1999), providing a context and an interpretation of what was seen, heard and felt in certain places (Irving \& Hoffman, 2014). For example, the legend of Māui in the creation story of Aotearoa New Zealand (Te Ika A Māui) features physical elements such as the Tararua Ranges, Wairarapa Moana (Lake Wairarapa) and Cape Palliser, and are all related to physical characteristics of the landscape. The North Island is defined as a great fish pulled from the sea with the ranges relating to the spine of the fish, the lake representing the freshwater eye of the fish and Cape Palliser as the nose of the fish.

Narratives are fundamental to culture, whether they are visually illustrated, spoken or sung. Potteiger and Purinton (1998) discuss the importance of narrative within and through landscape as a way in which people shape and make sense of their lived experience (Barrett, 2013). Stories and events link to personal experiences of time, place, memory and other intangible and tangible aspects of a landscape. Similarly, Brinkhuijsen (2007) suggests narratives can provide orientation in time and space while adding identity of individual and place. In addition, stories give places identity as they go beyond the visual cues and symbols and can embrace our senses through texture, light and sound. "We live in a world of stories" (Potteiger \& Purinton, 1998, p. 1). The places we occupy are the background for these stories. The visual structure of the stories facilitates the retelling and sharing, allowing for an engaging medium that has potential in the realm of landscape architecture. This process can simultaneously produce a design with aspects of imagination and perception, resulting in a more attractive and understandable landscape and allowing for stories to be remembered as one progresses on a journey from one point to another. Further testing of the design experiments and visualisation of oral narratives in this application with a wider sample of participants would allow for more specific data to be collected and subsequently greater in-depth analysis.

\section{Technology and landscape}

The integration of Māori values and processes allowed a deeper level of thinking on the relationship between people and the landscape. This also influenced the way the design of the physical elements of that landscape was approached, their relationship to the land and the underlying cultural values and narratives that gave identity to place. The use of current technology allowed the multifaceted meaning of the landscape to be fully portrayed. In Heidegger's essay, "The Question Concerning Technology", he questions the relationship of human existence with the essence of technology. Heidegger (1977) points out that technological objects are means for ends and are built and operated by human beings, but the essence of technology is something else entirely. It depends on our manipulation of technology in the proper manner as a means. He explains how technology should be interpreted as a way of "bringing-forth" or a "way of revealing". Bringing-forth becomes a method of bringing what is concealed into unconcealment, therefore revealing. This means that everything we perceive or think of or interact with "emerges out of concealment into unconcealment" in Heidegger's (1977, p. 5) words. Landscape already has many layers, most that are not always visible like, for example, the narratives and history of that landscape. Technology adds a further layer to the physical world around us and also provides a way to engage with some of those unseen elements. The challenge for indigenous communities lies in developing forms of visual representation which remain culturally relevant but at the same time are more permeable, balanced and multi-sensorial while "depict tangible and intangible elements, sites of dispute or reconciliation, competing foregrounds and backgrounds, memories and intergenerational memories, and non-linear understandings of time and space" (Brown \& Nicholas, 2012, p. 320).

However, technology also embodies a specific way of revealing the world, a revealing in which humans take power over reality. According to Heidegger (1977), the truth in the relationship between technology and "being" 
can be revealed through the use and manipulation of technological intervention. Technology can become a manifestation of the understanding of being if it is reliable but not a tool of enslavement. In landscape architecture, technology is currently used as a representational tool and as a data collection method, and the discourse of technology in the literature is largely related to the use of digital prototyping and design technologies. This research highlights the importance of an expanded role for technology in the landscape as a means of communication. As the capabilities of technology advance, the possibilities in relation to landscape and other disciplines also increase.

Virtual reality and AR are increasingly becoming assets for the representation of projects and allow greater engagement with the design process and its outcomes. Unlike the immersive environments of virtual reality that are designed to replace the real world with a simulated environment, AR supplements the existing reality with data that coexist with the real world (Azuma, 1997). However, while AR technologies have been available for some time, only recently have these technologies gained momentum due to commercial applications and easy interfaces, where content can be easily populated by a layperson and there is no requirement for programming skills. Due to the user-friendliness of AR, its applicability has extended into many disciplines in the built environment, such as landscape architecture, as a teaching and learning tool (Squire, 2010; Squire \& Klopfer, 2007).

In Walliss and Rahmann's (2016) book, Landscape Architecture and Digital Technologies, the authors discuss the opportunities and constraints of digital technologies and landscape architecture. Benefits such as the increased ability of collaboration and wider circles of knowledge/data to work with advanced modelling software to visualise designs are approached. However, the "power of digital prototyping lies in its possibility to connect the virtual with the physical space" (Walliss \& Rahmann, 2016, p. 220). The capacity to overlay the physical world with cultural values and artefacts that augment rather than replace is critical to this research as it allows the coexistence of culture and layered meanings of place. For example, Moore (2016) uses a merging of technology and history, allowing for an enhanced adaptation of an existing historic tour in the Civil Rights Heritage Centre in Indiana. Connecting the physical world with the digital has facilitated a new interface of experience that is constantly developing and captivating different age groups.

One of the major issues of technology today includes the dependence of the younger generations on technology; it is a part of their education, their entertainment and is dominant in the communication of their relationships (Gardner \& Davis, 2013). The recent use of AR is modernising history and providing opportunities for a greater engagement with traditional cultural and social values. This offers a bridge between the younger generations and their elders and the prospect of learning their history as an "enhanced version of reality created by the use of technology" (Moore, 2016 , p. 4). In sum, the use of AR enables new tactical possibilities for connecting and interpreting cultural landscapes in three ways: (a) users have the temporal and personal control to when and how the augmented simulations come into existence, (b) the augmented simulation and its digital content are site-specific and can only be accessed on site by the user and (c) the interactive nature of the augmented simulation as it allows the users to create their own representations of the site. For these reasons, to utilise technology in the study of cultural landscapes, AR offers unique qualities and has the potential to become a preferred technology.

While the benefits outweigh the disadvantages, AR still presents some limitations in terms of functionality. The main issue includes the requirement of a smart phone or device, which not everyone has. A secondary limitation relates to the trigger or marker image. At times, it was difficult to activate the trigger image to unlock the digital information for a specific site. Creating an AR simulation for an outdoor experience is very difficult when compared with indoor simulations due to the constant changing light conditions and inconsistent features of the landscape. For this reason, further testing is needed to develop a markerbased system that can be designed and used through structural landscape elements and to which digital information can be loaded on the environment. One of the challenges of many AR applications is the need for a Wi-Fi or mobile data connection through cell phone reception. This limitation was overcome in this experiment by using HP Reveal as an offline app that could read the trigger image on site and the associated digital information. As future testing, the use of geo-location-based AR applications may allow digital elements to be presented without the need for a trigger image.

Augmented reality also has the ability to connect people across great distances and create a link that was not there before. The risks of drawing people away from face-to-face interaction are present; however, research finds that technology has the ability to be used to encourage social interaction rather than remove it (Mohammed-Amin, 2010). An important consideration for future developments is for the app to be more interactive through an activity or interactivity at the location of the story. For instance, after the experience of $\mathrm{AR}$ in an environment, users could record their personal reflections and, for example, upload them in an online space or contribute to the story location on the app. The greater the opportunities for social connection, the greater the interest and sustained use.

\section{Conclusion}

Technology increasingly forces us to confront issues related to social and cultural interaction. It mediates user experiences and practices by creating flexible digital environments that tap onto the physicality of our landscapes. This study addressed how oral narratives of Aotearoa New Zealand's landscape could be reimagined and represented through the merging of existing landform and AR. Augmented reality is a growing technology that caters for interaction and engagement without completely removing the individual from the real world and the existing environment. It can bridge the gap between the tangible and the intangible landscape by proving an engaging medium for disseminating knowledge 
and contributing to the construction of a sense of place and identity. Similarly, AR can also provide the opportunity to foster new social interactive technology applications, which can encourage people to get out and interact with each other face-to-face. The popular mobile gaming application "Pokemon Go" is a great example of this, using the existing environment and overlaying digital information in a way that encourages social interaction.

The ability to engage directly with the existing environment and tell stories through this medium provides strong potential in the realm of cultural landscapes. While other media, such as virtual reality, completely remove the individual from the surroundings they are in, AR is grounded in the existing conditions and environment and is fully immersed in the current time and place. The potential of this technology for reproduction and reinterpretation of space is thereby realised through the layering of history while retaining the existing landscape. From an indigenous perspective, AR can allow the reassembling of taonga (treasures) in a range of forms, either through material objects, spoken word or text, or through artefacts that are commonly lodged in museums and libraries. However, the artefacts usually retained in minds, bodies and homes of whānau and iwi members, often living far from their traditional tribal areas, benefit the most from AR (Ngata et al., 2012). The results demonstrate that the use of AR as a means of revealing and understanding human existence within a cultural setting is valuable for interpreting the narrative of a site and how a sounder methodology for the design of physical reality and AR can evoke emotive qualities. The research finds that AR can be an effective tool for layering digital information on an existing and rich environment to show a historic or social narrative and ultimately safeguard indigenous cultures that struggle to protect and disseminate their oral traditions.

\section{Declaration of conflicting interests}

The author(s) declared no potential conflicts of interest with respect to the research, authorship, and/or publication of this article.

\section{Funding}

The author(s) received no financial support for the research, authorship, and/or publication of this article.

\section{Glossarya}

hongi- pressing noses in greeting

houhanga rongo-establishment of peace or peacemaking

iwi-extended kinship group, tribe

mahi tahi- to work together, collaborate or cooperate

manuhiri-visitors

mauri-life force

Ngāti Kahungunu ki Wairarapa-Māori iwi located along eastern coast of the North Island of Aotearoa New Zealand kai-food

kaitiakitanga—-guardianship

karanga-ceremonial call to welcome visitors onto a marae

karakia-prayer or chant

koha-gift or offering

pōhiri or pōwhiri-traditional Māori welcome ceremony on a marae

tangata whenua-local hosts, people born of the whenua, that is, of the placenta and of the land where the people's ancestors have lived and where their placenta is buried

taonga - treasure, applied to anything considered to be of value, including socially or culturally valuable objects, resources, phenomenon, ideas and techniques

tapu - a person, place or thing is dedicated to an atua (god) and is thus removed from the sphere of the profane and put into the sphere of the sacred. It is untouchable, no longer to be put to common use

Te Ika-a-Māui-story of the great fish of Māui, known as the North Island of Aotearoa New Zealand

tikanga - customs and traditions

tuku—offering

tūrangawaewae-domicile, place where one has the right to stand

waiata tautoko — support song

Wairarapa Moana-Lake Wairarapa

wero_-challenge at a pōhiri or pōwhiri

whaikōrero-formal speeches usually made by men during a pohiri or pōwhiri and other gatherings

whānau—extended family

whakarāmemene — bringing together or assembling

whenua - landscape, land or placenta of a newborn child

aDefinitions based on Moorfield (2005).

\section{ORCID iD}

Bruno Marques (iD https://orcid.org/0000-0002-4761-8225

\section{References}

Azuma, R. T. (1997). A survey of augmented reality. Presence: Teleoperators and Virtual Environments, 6, 355-385. doi:10.1162/pres.1997.6.4.355

Barrett, J. (2013). Virtual worlds and indigenous narratives. In R. Teigland \& D. Power (Eds.), The immersive Internet: Reflections on the entangling of the virtual with society, politics and the economy (pp. 77-91). Hampshire, UK: Palgrave Macmillan.

Borell, B. (2005). Living in the city ain't so bad: Cultural identity for young Māori in South Auckland. In J. Liu (Ed.), New 
Zealand identities (pp. 191-206). Wellington, New Zealand: Victoria University Press.

Brinkhuijsen, M. (2007, January). Legible landscapes: The use of narratives in landscape design for leisure and tourism in Dutch cultural landscapes. ASA Conference (Association of Social Anthropologists), London, England.

Brown, D., \& Nicholas, G. (2012). Protecting indigenous cultural property in the age of digital democracy: Institutional and communal responses to Canadian First Nations and Māori heritage concerns. Journal of Material Culture, 17, 307-324.

Burgess, J. (2006). Hearing ordinary voices: Cultural studies, vernacular creativity and digital storytelling. Continuum, 20, 201-214. doi:10.1080/10304310600641737

Chris, C. (2000). A framework for addressing Māori knowledge in research, science and technology. Pacific Health Dialog, 7, 62-69.

Cosgrove, D. (2006). Modernity, community and the landscape idea. Journal of Material Culture, 11, 49-66. doi:10.1177/1359183506062992

Crotty, M. (1998). The foundations of social research: Meaning and perspective in the research process. St Leonards, New South Wales, Australia: Allen \& Unwin.

Dakin, S. (2003). There's more to landscape than meets the eye: Towards inclusive landscape assessment in resource and environmental management. The Canadian Geographer/Le Géographe canadien, 47, 185-200. doi:10.1111/1541-0064. t01-1-00003

Damala, A., Cubaud, P., Bationo, A., Houlier, P., \& Marchal, I. (2008, September). Bridging the gap between the digital and the physical: Design and evaluation of a mobile augmented reality guide for the museum visit. Paper presented at the 3rd International Conference on Digital Interactive Media in Entertainment and Arts (DIMEA '08), New York, NY.

de Souza e Silva, A. (2006). From cyber to hybrid: Mobile technologies as interfaces of hybrid spaces. Space and Culture, 9 , 261-278. doi:10.1177/1206331206289022

Eve, S. (2012). Augmenting phenomenology: Using augmented reality to aid archaeological phenomenology in the landscape. Journal of Archaeological Method and Theory, 19, 582-600.

Gardner, H., \& Davis, K. (2013). The app generation: How today's youth navigate identity, intimacy, and imagination in a digital world. New Haven, CT: Yale University Press.

Gentz, N., \& Kramer, S. (2006). Globalization, cultural identities, and media representations. Albany: State University of New York Press.

Girot, C. (1999). Four trace concepts in landscape architecture. In J. Corner (Ed.), Recovering landscape: Essays in contemporary landscape architecture (pp. 59-67). New York, NY: Princeton Architectural Press.

Heidegger, M. (1977). The question concerning technology, and other essays. New York, NY: Harper \& Row.

Irving, L., \& Hoffman, J. (2014). Nyungar place stories pilot: Using augmented reality for indigenous cultural sustainability. In B. Hegarty, J. McDonald, \& S.-K. Loke (Eds.), Rhetoric and reality (pp. 367-377). Retrieved from http://ascilite.org/conferences/dunedin2014/files/fullpapers/328-Irving.pdf

Kalay, Y. E. (2007). Preserving cultural heritage through digital media. In Y. Kalay, T. Kvan, \& J. Affleck (Eds.), New heritage (pp. 17-26). London, England: Routledge.

Kemal, S. (1999). Landscape, natural beauty and the arts. Cambridge: Cambridge University Press.

King, M., Smith, A., \& Gracey, M. (2009). Indigenous health part 2: The underlying causes of the health gap. The Lancet, 374, 76-85. doi:10.1016/s0140-6736(09)60827-8
Lieberman, A. E. (2009). Taking ownership: Strengthening indigenous cultures and languages through the use of ICTs. Washington, DC: Academy for Educational Development.

Mark, G., \& Lyons, A. (2010). Māori healers' views on wellbeing: The importance of mind, body, spirit, family and land. Social Science \& Medicine, 70, 1756-1764.

Marques, B., Grabasch, G., \& McIntosh, J. (2018). Fostering landscape identity through participatory design with indigenous cultures of Australia and Aotearoa/New Zealand. Space and Culture. Advance online publication. doi:1206331218783939

McIntosh, J., Marques, B., \& Hatton, W. (2018). Indigenous cultural knowledge for therapeutic landscape design. In I. de Sousa Rosa, J. C. Lopes, R. Ribeiro, \& A. Mendes (Eds.), Handbook of research on methods and tools for assessing cultural landscape adaptation (pp. 28-52). Hershey, PA: IGI Global.

McKenzie, D. F. (1985). Oral culture, literacy \& print in early New Zealand: The treaty of Waitangi. Wellington, New Zealand: Victoria University Press.

Mennella, V. (1997). Quality of the environment and the development of rural areas. Journal of Environmental Management, 69, 93-104.

Menzies, D., Renata, A., \& Whaanga-Schollum, D. (2016). Connecting eco-systems and belief systems through regeneration and innovation. X-Section Journal, 6, 98-105.

Merriam Webster. (2018). Culture. Retrieved from https://www. merriam-webster.com/dictionary/culture

Metge, J. (1999). Time \& the art of Maori storytelling. The Journal of New Zealand Studies, 8(1). doi:10.26686/jnzs.v8i1.339

Mohammed-Amin, R. K. (2010). Augmented reality: A narrative layer for historic sites (Master's thesis). University of Calgary, Calgary, Alberta, Canada.

Moore, M. S. (2016). A portal through time: An enhanced, immersive, adaptation of the Civil Rights Heritage Center's African-American landmark tour. Chicago. Retrieved from http://www.miriammooredesign.com/portal.html

Moorfield, J. C. (2005). Te Aka: Māori-English, English-Māori dictionary and index. Harlow, UK: Longman.

Murthy, D. (2008). Digital ethnography: An examination of the use of new technologies for social research. Sociology, 42, $837-855$.

Murton, B. (2012). Being in the place world: Toward a Māori "geographical self". Journal of Cultural Geography, 29, $87-104$

Muru-Lanning, M. (2012). Māori research collaborations, mātauranga Māori science and the appropriation of water in New Zealand. Anthropological Forum, 22, 151-164.

Ngata, W., Ngata-Gibson, H., \& Salmond, A. (2012). Te Ataakura: Digital taonga and cultural innovation. Journal of Material Culture, 17, 229-244.

Panelli, R., \& Tipa, G. (2007). Placing well-being: A Māori case study of cultural and environmental specificity. EcoHealth, 4, 445-460. doi:10.1007/s10393-007-0133-1

Peet, R., \& Watts, M. (2004). Liberation ecologies: Environment, development and social movements. London, England: Routledge.

Phillips, J. (2007). Perceptions of the landscape-A romantic landscape. Teara.govt.nz. Retrieved from http://www.TeAra. govt.nz/en/perceptions-of-the-landscape/page-1-4

Potteiger, M., \& Purinton, J. (1998). Landscape narratives: Design practices for telling stories. New York, NY: John Wiley.

Robertson, I., \& Richards, P. (2003). Studying cultural landscapes. London, England: Arnold Publications. 
Royal, C. (2007). Papatūānuku-The Land. Teara.govt.nz. Retrieved from https://teara.govt.nz/en/papatuanuku-theland/page-1

Squire, K. (2010). From information to experience: Place-based augmented reality games as a model for learning in a globally networked society. Teachers College Record, 112, 2565-2602.

Squire, K., \& Klopfer, E. (2007). Augmented reality simulations on handheld computers. Journal of the Leaning Sciences, 16 , $371-413$.

Vining, J., Merrick, M. S., \& Price, E. A. (2008). The distinction between humans and nature: Human perceptions of connectedness to nature and elements of the natural and unnatural. Human Ecology Review, 15(1), 1-15.
Vlahakis, V., Karigiannis, J., Tsotros, M., Almeida, L., Stricker, D., Gleue, T., \& Ioannidis, N. (2001). Archeoguide: First results of an augmented reality, mobile computing system in cultural heritage sites. Retrieved from http://publica.fraunhofer.de/documents/N-7972.html

Walliss, J., \& Rahmann, H. (2016). Landscape architecture and digital technologies. New York, NY: Routledge.

Williams, L. (2003). Empowering social action through narratives of identity and culture. Health Promotion International, 18, 33-40. doi:10.1093/heapro/18.1.33

Yates, A. (2006). On whenua, landscape and monumental interiors. IDEA: Interior Design/Interior Architecture Educators Association Journal, 7, 103-113. 